\title{
Das geopolíticas clássicas à geoeconomia: a importância da segurança humana no Pós-Guerra Fria
}

\author{
Claudia Santos ${ }^{1}$
}

Resumo: O período Pós- Guerra Fria nas Relações Internacionais representou um momento de diversas mudanças conceituais, introdução de novos temas na agenda internacional e a emergência de novos atores. O presente estudo utiliza-se de pesquisa bibliográfica para compreender a crise das geopolíticas clássicas no Pós-Guerra Fria relacionadas ao conceito tradicional de Segurança e os processos que culminaram na criação do conceito de Segurança Humana partindo da hipótese de que ela não se apresenta como uma contraposição ao conceito tradicional de Segurança que tem como ator central os Estados, mas como um conceito complementar que busca introduzir a questão do indivíduo nos debates. Para se verificar esta hipótese o estudo se centrará na análise das implicações que a geoeconomia causou no Pós-Guerra Fria, na qual a divisão do mundo se torna econômica (Norte/Desenvolvidos e Sul/Subdesenvolvido) e não mais ideológica (Capitalismo/Comunismo). Os vários conceitos de Segurança vêm adquirindo importância internacional principalmente nos círculos de policy making visto as necessidades de um mundo globalizado, no qual as relações e negociações tornam-se transnacionais. No caso da geoeconomia, a Segurança Humana faz-se ainda mais necessária visto os problemas causados pelo neoliberalismo em países subdesenvolvidos, como a pobreza e no seu extremo, conflitos regionais. Estas características deste modo exigem que o Estado não veja a questão de Segurança apenas por uma dimensão, mas de maneira interdisciplinar levando em consideração as diversas variáveis existentes e as suas interações. O que este artigo pretende é contribuir para o entendimento de uma nova concepção multidimensional de Segurança apresentando a Segurança

\footnotetext{
Graduanda em Relações Internacionais pelo Centro Universitário Internacional UNINTER, Curitiba, Brasil, madamebutterfly.c@gmail.com.
} 
Humana com um conceito a ser levado em consideração em um período geoeconômico.

Palavras-Chave: Geopolítica. Geoeconomia. Segurança Humana. PósGuerra Fria.

Abstract: The period Post-Cold War in International Relations was a moment of several conceptual changes, introduction of new issues on the international agenda and the emergence of new actors. This study makes use of literature to understand the crisis of classical geopolitics in the post-Cold War related to the traditional concept of security and the processes that led to the creation of the concept of Human Security on the assumption that it does not present itself as a opposed to the traditional concept of security that has as its central actor states, but as a complementary concept that seeks to introduce the issue of individual debates. To verify this hypothesis the study will focus on analyzing the implications of geo-economics caused the Post-Cold War, in which division of the world becomes economic (North / South and Developed / underdeveloped) and no more ideological (Capitalism / Communism). The various concepts of security have acquired international importance especially in policy making circles seen the needs of a globalized world, where relationships and negotiations become transnational. In the case of geo-economics, Human Security becomes even more necessary as the problems caused by neoliberalism in underdeveloped countries, such as poverty and its extreme regional conflicts. These features thus require that the state does not see the issue of Security by only one dimension, but an interdisciplinary basis, taking into account the various existing variables and their interactions. What this article aims to contribute to the understanding of a new multidimensional conception Security with Human Security presenting a concept to be considered in a geo-economic period.

Keywords: Geopolitics. Geoeconomics. Human Security. Post-Cold War. 


\section{Introdução}

O tema abordado é a importância da Segurança Humana em um mundo Geoeconomicamente organizado. O surgimento do conceito de Segurança Humana está intimamente ligado a um momento de grandes mudanças no cenário internacional, notadamente a desintegração do Bloco Soviético e o fim da Guerra Fria que também denotam o marco da crise das geopolíticas Clássicas e o começo da geoeconomia.

Simultaneamente com estes acontecimentos também acontecia mundialmente o fenômeno da globalização que mudou as regras internacionais facilitando o fluxo de capital e tecnologia entre países quebrando deste modo as barreiras nacionais. Neste período também emergem os novos atores não estatais no cenário internacional surgindo como pontes entre comunidades e nações, mudando desta forma o papel do Estado e ancorando questionamentos sobre a concepção tradicional de poder.

Mas a mudança na realidade global provocada pela globalização não trouxe só benefícios. Com a hegemonia tanto geopolítica quanto econômica dos Estados Unidos no Pós-Guerra Fria, as disparidades entre norte e sul, desenvolvidos e subdesenvolvidos é 
latente, mesmo com a emergência dos BRICS $^{2}$ ainda se nota problemas estruturais nestes países, como instabilidade política, fome e desemprego. Sendo assim, a geoeconomia se demonstra desfavorável aos países pobres e subdesenvolvidos, a exemplo desta "geoeconomia da diferença" está a incidência de conflitos regionais em países pobres, principalmente da África.

É deste ponto que surge a problemática que será analisada no decorrer do estudo. Será que Segurança Humana teve importância como uma nova abordagem de Segurança que contempla um cenário PósGuerra Fria que contribuiu para o terceiro debate de Relações Internacionais iniciado nos anos 70 com a inserção de novos atores e com foco na estrutura do sistema internacional a fim de propor uma visão mais ampla dos acontecimentos? Visto que os anos 90 sugerem uma revisão dos conceitos tradicionais de Segurança, além de se caracterizarem como um período de aumento de conflitos regionais que afetam de forma direta o indivíduo.

$\mathrm{O}$ artigo justifica-se pela relevância do tema no século XXI nas Relações Internacionais, no qual a emergência de uma nova ordem mundial exige medidas que se adequem ao mundo Pós-Guerra Fria, um mundo que exige cooperação mútua, no qual não deve haver o

\footnotetext{
${ }^{2}$ Para Tadjbakhsh (2007) a adoção da segurança humana nas políticas domésticas e exteriores permite um aumento da participação de países de potência média no cenário internacional.
} 
pressuposto de uniformidade, mas de diversidade em que aspectos de bem comum vem à frente de aspectos como política, religião, economia, etc. aderindo à percepção de "vizinhança global". Por conta das diversas mudanças e momentos de transição que o mundo vem passando em diversos aspectos é que se nota a importância de novos conceitos que resguardem os direitos dos indivíduos e que impeçam as geopolíticas clássicas ou até mesmo a geopolítica de tornarem-se instrumentos de imperatividade e de dominação.

A hipótese apresentada é a de que o conceito de Segurança Humana não se contrapõe ao conceito de Segurança tradicional, mas o complementa. Ao trazer novos atores aos debates, o conceito de Segurança Humana não ignora o papel central do Estado nas Relações Internacionais, mas alerta para o fato de que o mundo Pós-Guerra Fria tem características diferentes do seu período anterior referentes à Primeira e a Segunda Guerra Mundial. Os conteúdos e temáticas dos conflitos atuais são mais complexos e demandam que novos instrumentos de análises sejam criados para darem conta de compreendê-los e para além disso, que sirvam de instrumentos de ação, sendo assim é neste contexto que surge o conceito de Segurança Humana.

Este trabalho tem como objetivo geral analisar o processo de crise das geopolíticas clássicas e o surgimento da Segurança Humana no período Geoeconômico. O ponto de partida para o Estudo será o PósGuerra Fria, período em que ocorrem mudanças significativas no 
cenário internacional e que permitem novos debates, como o de Segurança Internacional.

Os procedimentos metodológicos utilizados serão a revisão bibliográfica para a análise dos conceitos de Segurança Humana, Geopolíticas Clássicas e Geoeconomia. A abordagem metodológica para o conceito de Segurança Humana parte da Descrição de Bernardo Sorj sobre o que é Segurança Humana, demonstrando que é uma concepção inovadora dentro das Relações Internacionais, tornando-se central para o debate da questão de gênero, por exemplo, com destaque às leis referentes aos Direitos Humanos dos indivíduos. Com relação as Geopolíticas Clássicas e a Geoeconomia o autor principal utilizado para análise será José William Visentini que traz importantes reflexões sobre o assunto nas Relações Internacionais.

\section{A crise das geopolíticas clássicas e o surgimento da geoeconomia}

O contexto Pós-Guerra Fria trouxe diversas mudanças para as Relações Internacionais, seja com relação aos questionamentos das suas teorias e conceitos, ou seja, pela mudança nos estudos acerca das tensões em conflitos. Nos últimos anos estas mudanças internacionais também se deram no âmbito da Geopolítica, sendo assim o campo de estudos se abriu espaço para estudos não somente para estrategistas, mas também para cientistas políticos e internacionalistas a fim de diversificar a compreensão das relações de poder. 
Os estudos geopolíticos contemporâneos se caracterizam desta forma "como uma problemática interdisciplinar" (VISENTINI, 2000, p. 11). Mas isto nem sempre foi assim. A Geopolítica por muito tempo, desde o seu princípio, concentrou como base de estudos e ação as guerras e as forças militares. Sendo assim, as Geopolíticas Clássicas muito se atrelavam à geoestratégia.

Segundo José Visentini (2000) o Pós-Guerra Fria foi um momento de importantes mudanças no cenário internacional, no qual se relativizam conceitos e surgem as chamadas "novas geopolíticas" da década de 80 que tem como objetivo "procurar explicar como se dará a disputa pela hegemonia mundial no século XXI" (VISENTINI, 2000, p. 12). O fato das novas geopolíticas terem surgido no período da globalização para o autor não é por acaso, já que foi o período de enfraquecimento dos Estados nacionais e ascensão de novos atores.

Quando ao surgimento da Geopolítica, Rudolph Kjellén é considerado o pai da Geopolítica clássica. Formado em Direito, Rudolph Kjellén nasce na Suécia e em 1905 escreve o livro que encabeça a disciplina de Geopolítica intitulado "As grandes potências". Para Rudolph Kjellén a geopolítica era "a ciência que estuda o Estado como organismo geográfico" (VISENTINI, 2000, p. 15). Para Kjellén a geopolítica possuía o caráter interdisciplinar, mas somente entre disciplinas específicas que eram: a ciência política, a geografia, a estratégia militar e a teoria jurídica do Estado. Para Kjellén, segundo Visentini (2000), a preocupação básica da geopolítica era o 106 
estabelecimento de determinado Estado internacional e a hegemonia, por isso a correlação desta busca com a necessidade dos Estados de se expandir territorialmente.

A crise da Geopolítica ocorre no período Pós-Segunda Guerra Mundial, visto os questionamentos e o "esgotamento de seus pressupostos fundamentais" (VISENTINI, 2000, p. 25). Um dos questionamentos à Geopolítica Clássica é que seus pressupostos fundamentais (População, Território e Capacidade Militar) não mais pressupõem que um Estado seja Potência mundial. Isto acontece devido a importância que se dá para a Revolução Técnico-Científica que diminuiu a importância dada aos recursos naturais com a criação da biotecnologia como um mecanismo para otimizar a produção.

O Pós-Guerra Fria demonstrou que para um Estado se tornar uma potência mundial para além do que atestavam as Geopolíticas Clássicas é necessário que ele possua "tecnologia moderna, com uma força de trabalho qualificada [...] e não aquele que possui basicamente um grande território, numerosa população, boa estratégia militar e armamentos pesados" (VISENTINI, 2000, p. 28)

Do ponto de vista de Edward N. Luttwat, estrategista militar norte-americano e cientista político, mencionado por Visentini (2000) é no Pós-Guerra Fria que as guerras militares são substituídas pelos conflitos econômicos, e quando surge a chamada Geoeconomia. Para Edward Luttwat os conflitos militares perdem importância frente aos 
econômicos, visto a força do comércio, que se consolida com o capitalismo Pós-Guerra Fria e a hegemonia norte-americana.

Com o surgimento da Geoeconomia há uma reinterpretação dos conflitos mundiais, já que diversos conflitos posteriores o período Pós-Guerra Fria tem ligação ou causas econômicas. Como no caso da África, um continente que sofre com diversos problemas entre eles o neocolonialismo, instabilidade política, fome, doenças e conflitos étnicos. Segundo um discurso do Secretário-Geral da ONU, Ban Kimoon

Os conflitos nascem onde há má governança, abusos dos direitos humanos e queixas sobre a distribuição desigual de recursos, riqueza e poder [...] As tensões aumentam quando as pessoas são excluídas, marginalizadas e têm negadas a participação significativa na vida política e social de seus países [...] A inquietação nasce onde as pessoas são pobres, sem emprego e sem esperança (ONU, 2013). 


\section{FIGURA 1: Divisão econômica do mundo}

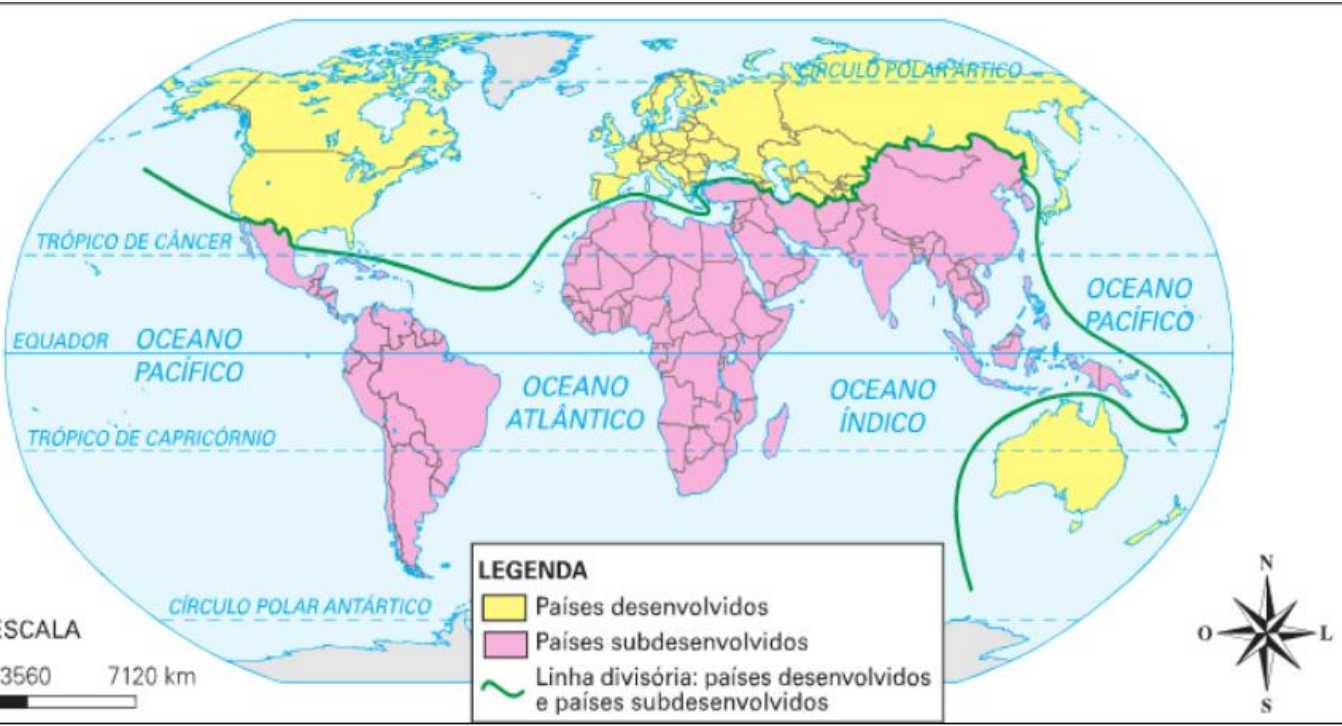

Países com economia instável e distribuição de renda desigual são muito mais vulneráveis social e politicamente do que países com economia ascendente e estável. Do século XX para o século XXI vemos uma grande diminuição de guerras propriamente ditas entre países. Mas a violência interna dos países aumentou significativamente.

Com relação às geopolíticas clássicas e a questão de segurança, devido os protestos da sociedade civil, de famílias que perderam seus parentes em combates ou em conflitos, nos últimos tempos houve mudanças nos objetivos e estratégias militares no Pós-Guerra Fria. Para Visentini (2000) com a ascensão do liberalismo no sistema internacional o que se busca é a conquista e a inserção do outro no mercado global, não mais o seu extermínio. 
Então as questões militares têm muito mais ênfase nos "misseis de precisão, sistemas de informação e de contrapropaganda mais sofisticados, aviões completamente informatizados e difíceis de serem detectados, que rapidamente bombardeiam pontos específicos com uma margem mínima de erro" (VISENTINI, 2000, p. 88), deste modo os misseis de precisão

[...] envolvem cada vez mais menos riscos para soldados, pois os reclames da sociedade civil contra as perdas de familiares são mais intensos hoje, e que não vão matar indiscriminadamente milhares ou milhões de pessoas e sim ser mais "cirúrgicos" no sentido de eliminar os pontos estratégicos do adversário (edifícios, aeroportos [...]) (VISENTINI, 2000, p. 89)

Também se destacam os acordos internacionais relacionados à Segurança e Defesa como o TNP - Tratado de proliferação nuclear, o tratado da proscrição dos testes nucleares, a convenção das armas químicas e biológicas e o regime de controle da tecnologia de misseis, no qual cada vez mais Estados vem assinando e renovando os mesmos.

Outra mudança nas Forças Armadas no Pós-Guerra Fria é a concepção de soldado que hoje está muito ligada ao mercado de trabalho, no sentido de angariar muito mais profissionais altamente capacitados como engenheiros, analistas de sistemas, entre outros, ao invés de focar na habilidade física - o que possibilitaria um maior 
ingresso de mulheres nas Forças Armadas ${ }^{3}$ - isto porque segundo Visentini (2000) os meios militares levam muito mais em consideração o conhecimento e a informação.

\section{Segurança Humana: um novo conceito das Relações Internacionais}

O conceito de segurança humana emerge do cenário pacífico decorrente do período Pós-Guerra Fria. Em 1994 o primeiro programa de desenvolvimento das nações unidas identificou a segurança humana com um "caminho a percorrer a partir daqui". O conceito de segurança que era apenas focado na militarização passou agora a ser incluído como a capacidade de segurança contra a fome, a doença e a repressão, bem como a proteção contra interrupções repentinas e prejudiciais nos padrões de vida diária.

Nas relações internacionais a Segurança Humana é vista como uma nova teoria ou conceito, até mesmo como um paradigma. Ela se mostra relevante para a formulação de Políticas Internacionais, pois abrange as mudanças nas relações internacionais e sobretudo para a interdependência entre nações e indivíduos. Muitos países já levam a Segurança Humana como um princípio da sua condução de Políticas Externas. Isto porque, assim como o conceito tradicional de Segurança é entendido como a proteção de uma nação às ameaças militares de

\footnotetext{
${ }^{3}$ Outro aspecto favorável as mulheres é que o alistamento nos EUA e em alguns outros países não é mais obrigatório, mas sim voluntário.
} 
outras nações, a Segurança Humana deve ser vista como a proteção da dignidade dos indivíduos.

Para Bernardo Sorj (2005) um dos teóricos que dissertam sobre a Segurança Humana, o autor a descreve como

[...] a defesa do conceito de segurança humana se baseia em particular na nova constelação internacional de atores políticos, posterior à Guerra Fria - em boa parte pelo fato de que hoje a insegurança física é causada mais por conflitos armados internos do que por guerras entre países. Tais conflitos podem ser guerras civis ou disputas mais indefinidas entre quadrilhas armadas ou grupos terroristas, às vezes com apoio direto ou indireto de Estados pouco comprometidos com os direitos humanos (SORJ, 2005, p. 41-42)

A segurança humana está intimamente ligada ao bem-estar, a justiça e a dignidade humana. Sendo assim dentro da Segurança Humana compreendem-se a Segurança Econômica, a Segurança Alimentícia, a Segurança à Saúde, a Segurança Ambiental, a Segurança pessoal, a Segurança a comunidade e a Segurança Política.

Para Tadjbakhsh (2007) não há apenas uma definição de Segurança Humana, pois esta pode vir desde uma estreita definição de prevenção da violência a uma abordagem mais compreensiva de desenvolvimento, Direitos Humanos e Segurança tradicional também. O que há são ideias híbridas, declarações, relatórios e análises, bem como críticas. 
Independente das críticas ao conceito de Segurança Humana sobre a possibilidade dele ser um conceito vago e sem utilidade analítica e prática, a Segurança Humana em contraposição à isto vem se apresentando cada vez mais presente também além das agendas políticas de muitos países, em Organizações Internacionais e nas Nações Unidas - ONU. Por estas e outras razões que o estudo da Segurança Humana nas relações internacionais no século XXI se mostra tão relevante.

A principal mudança decorrente do período Pós-Guerra Fria é o fim do conflito bipolar e a tendência a uma maior interdisciplinaridade, aceleração da globalização e fragmentação sociocultural, por meio do capitalismo. Características que também são designadas para a Geoeconomia. Nos anos 70 houve críticas ao Realismo por sua incapacidade de lidar com o fenômeno da interdependência e da transnacionalização.

Segundo Tadjbakhsh (2007) a Segurança Humana também desafia moralmente o realismo, ao criticar o conceito se Segurança com como sendo uma prioridade do Estado (raison d'état) e que levasse apenas em consideração a Segurança do território e não a Segurança das pessoas, em um sentido de razão da existência.

Outro questionamento feito pela Segurança Humana é quanto à soberania do Estado como o único provedor der segurança, realçando as dimensões supranacionais do conceito, e permitindo ao Estado um papel proeminente como condição necessária para a segurança 
individual. A crítica é que o Estado não é o único ator político existente nas relações internacionais, por isso da necessidade de criar uma rede de diversos atores, feito por Estados, ONGs, Organizações Internacionais e individuais habilitados.

\section{FIGURA 2: Segurança Humana: Segurança, Direitos e Igualdade}

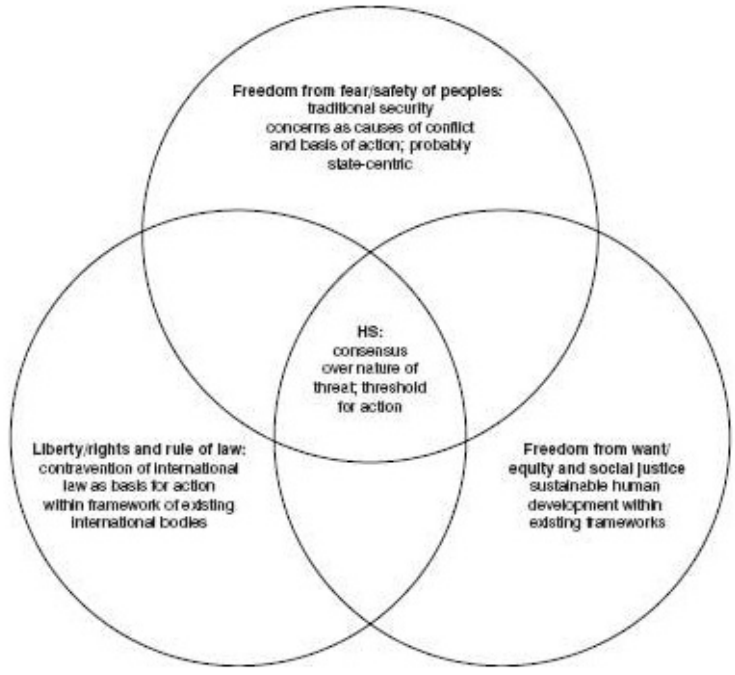

FONTE: Tadjbakhsh (2007) ${ }^{4}$

A Figura 2 tem como objetivo demonstrar a relação de consenso que precisa existir entre Segurança, Direitos e Igualdade que precisa haver para a existência da Segurança Humana. Quanto as superações necessárias para que a Segurança Humana seja efetivada, é necessário que cada um dos pontos supere suas próprias dificuldades. No caso da Segurança é necessário que o conceito tradicional de

${ }^{4}$ S/P: Sem Paginação, Livro e-book (Amazon) Download Kindle. 
Segurança compreenda que muitas vezes sua visão é estadocêntrica. Os Direitos levados ao âmbito internacional devem reconhecer que suas regras entre os Estados são contraditórias e o Reconhecimento da Igualdade como base para o desenvolvimento humano.

\section{FIGURA 3: Pirâmide da Segurança}

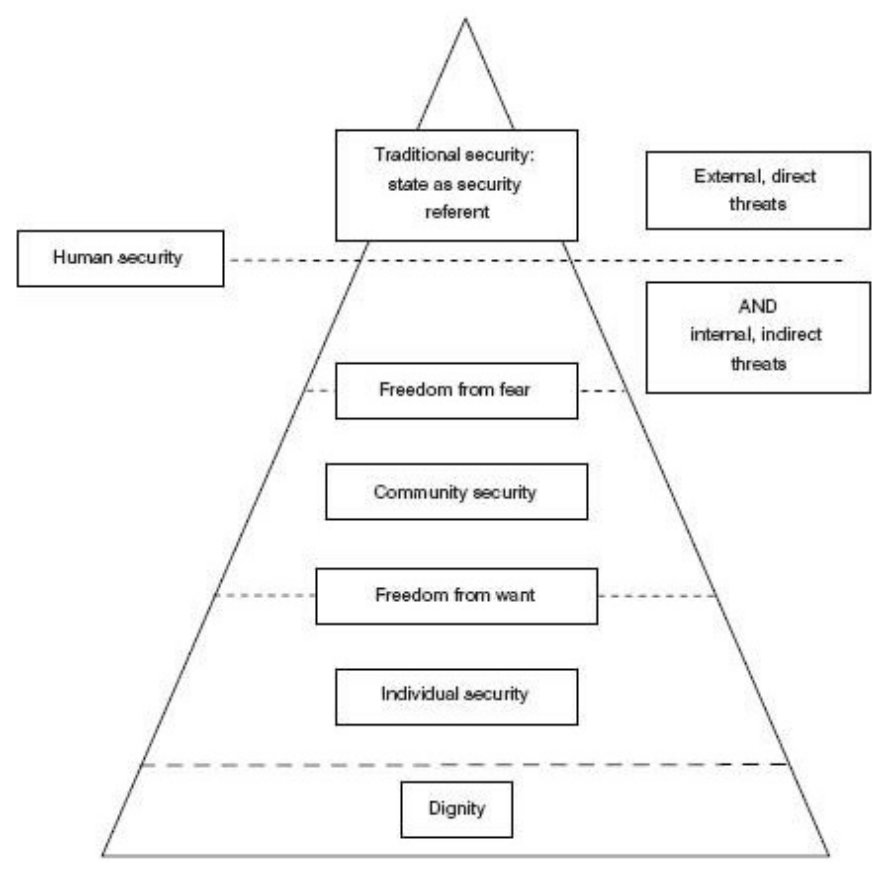

FONTE: Tadjbakhsh $(2007)^{5}$

A figura 3 apresenta os diversos conceitos em forma de pirâmide e de prioridade, pode-se notar que no topo da pirâmide está o conceito tradicional de Segurança ligado ao Estado que se direciona ao

${ }^{5}$ S/P: Sem Paginação, Livro e-book (Amazon) Download Kindle. 
externo e suas ameaças diretas. Com o desenvolvimento do conceito de segurança o foco para ser exclusivo no ser humano.

\section{FIGURA 4: A Segurança Humana e Ameaças}

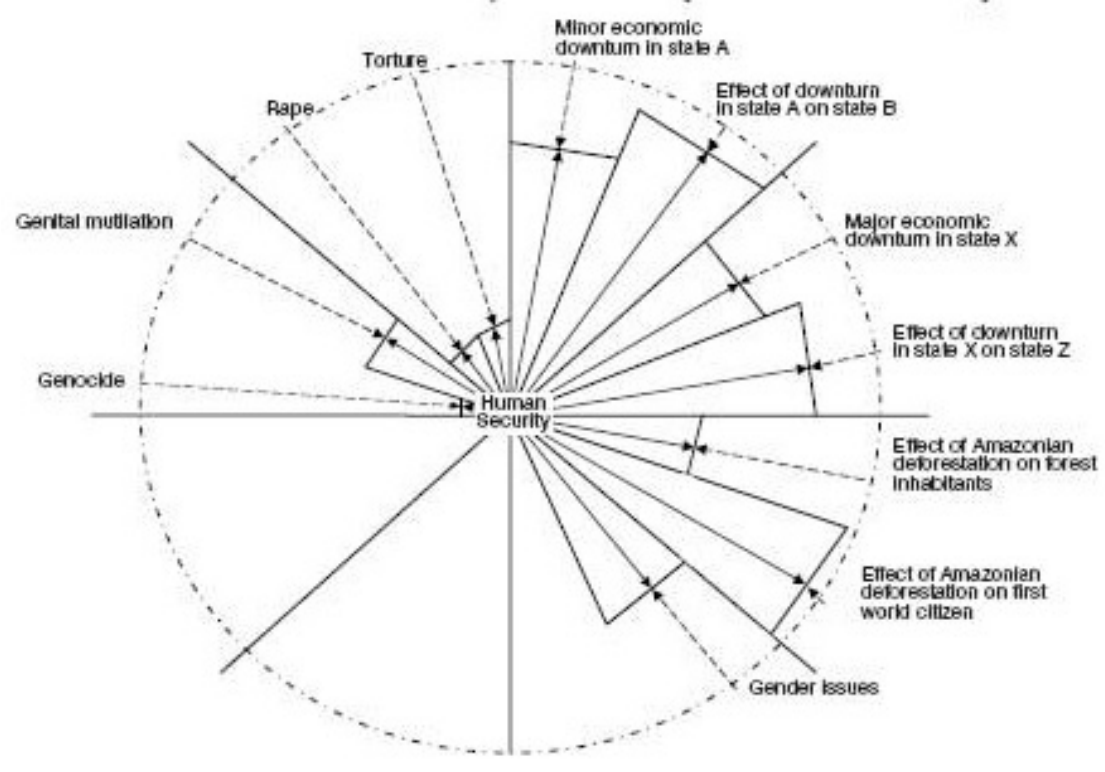

FONTE: Tadjbakhsh $(2007)^{6}$

$\mathrm{Na}$ figura 4 este círculo mostra as variedades de ameaças que podem ser consideradas dentro do quadro da segurança humana e as subjetividades inerentes a isso. De um jeito engenhoso a segurança humana pode integrar tanto ameaças de segurança objetivas quanto subjetivas. Quanto mais próxima a linha de cada ameaça está do centro do círculo mais provável se torna de que haverá um consenso acerca da

${ }^{6}$ S/P: Sem Paginação, Livro e-book (Amazon) Download Kindle. 
ameaça, como no caso do genocídio. Igualmente quanto mais próximo as linhas das ameaças estão da borda, mais subjetiva é a percepção acerca da ameaça. Deste modo, o consenso acerca de uma ameaça será maior se este for considerado de forma generalizada ser mais sério.

\section{A contribuição feminista para a segurança humana}

Apesar das diversas vertentes do feminismo, todas concordam acerca da busca pela equidade e compreendem o patriarcalismo como algo inerente às instituições, sendo assim suas críticas a abordagem tradicional do realismo tem contribuído para alterar paradigmas de Segurança.

Para Tadjbakhsh (2007) o feminismo desafia a doutrina realista do Estado, no qual a figura central e ator principal é o "homem soberano" que é o símbolo do poder. O feminismo desta forma culpa o realismo por endossar um entendimento "masculinista" do mundo e de status do homem. Neste sistema é o "homem soberano" quem faz as escolhas racionais e legitima a violência, as mulheres desta forma se apresentam como as excluídas e controladas direta, através da violência física, ou indiretamente, pelas concepções e ideologias que endossam papéis diferentes.

Dentro do quadro da Segurança Humana a exclusão feminina e das demais minorias é contraposto ao realismo e ao neorrealismo que através de um subterfugio de anarquia, mantem as mulheres longe de 
discernirem os padrões de patriarcalismo e a realidade em toda a sua complexidade.

O feminismo também tem desafiado a visão do militarismo como defensor do interesse nacional e afirma que a segurança do Estado também deve envolver estratégias não militares como a negociação. Sendo assim, "Feminist geopolitics is not an alternative theory of geopolitics, but an approach to global issues with feminist politics in mind ${ }^{7, "}$ (Tadjbakhsh, 2007).

As feministas se opõe à militarização e a entendem como um aspecto da masculinidade. Feministas de qualquer modo acreditam que a concepção de Segurança Humana precisa ser generalizada, porque mesmo dentro de um quadro radical como "segurança das pessoas", é o homem quem consegue os privilégios e os papeis especiais e as necessidades das mulheres são assumidas por agendas masculinas.

A figura 5 a seguir é um quadro que contempla a teoria realista, liberal construtivista, feminista e o conceito de Segurança e busca demostrar de forma simplificada como cada uma compreende a questão da Segurança.

As perguntas e as variáveis das teorias de Relações Internacionais e o conceito de Segurança Humana são as Seguintes:

Qual o estado do sistema internacional?

\footnotetext{
${ }^{7}$ Tradução Livre: A Geopolítica feminista não é uma teoria alternativa da Geopolítica, mas uma abordagem aos problemas globais com a política feminista em mente.
} 
Para a Segurança Humana se apresenta como inseguro visto as desigualdades e a pobreza, para o realismo ele é anárquico, bem como para o liberal, para o construtivismo o cenário internacional é resultado das interações e para ao feminismo é baseado na masculinidade.

Principais referenciais de Segurança?

O principal referencial de Segurança para o conceito de Segurança Humana é o indivíduo, para realismo é o Estado, para o liberalismo é o Estado e as Instituições Internacionais, para o construtivismo são os indivíduos, as ONGs e a sociedade civil e para o feminismo são as mulheres.

Determinantes da Segurança?

Para a Segurança Humana é a economia, a saúde, o meio ambiente, a política, entre outros. Para o realismo é a segurança nacional e militar, para o liberalismo é a segurança de mercado, do Estado e das Instituições, para o construtivismo é a segurança cultural e de identidades e para o feminismo é o empoderamento ${ }^{8}$ das mulheres e de outras classes.

Interesses do Estado?

Para a Segurança Humana é a proteção dos indivíduos, para o realismo é a busca pelo poder, para o liberalismo é a busca pela

\footnotetext{
${ }^{8}$ Isto faz referência ao pressuposto de Segurança pessoal da Segurança Humano, no qual as ameaças podem ser diretas contra mulheres como violência doméstica, abuso ou estupro. E a necessidade de um empoderamento de gênero e desmilitarização para segurança política da comunidade.
} 
independência econômica, política e militar, para o construtivismo é a mudança na percepção da população e para ao feminismo é a criação da igualdade de gênero.

\section{A segurança significa?}

Para a Segurança Humana significa o empoderamento e a proteção dos indivíduos, par ao realismo é a proteção do Estado, para o idealismo é a cooperação e a interdependência, para o construtivismo é a criação de normas pacíficas pelas instituições internacionais e para o feminismo é a segurança e a proteção dos Direitos de gênero.

O papel dos atores na Segurança?

Para a Segurança Humana significa o empoderamento dos indivíduos e da sociedade civil, para o realismo seria os executivos do Estado e os comandantes do exército no comando da segurança nacional, para o liberalismo seriam os atores emergentes do processo democrático, para o construtivismo são os múltiplos atores e para o feminismo são as mulheres como sujeitos de mudança.

Noção e papel do poder?

Para a Segurança Humana é o poder coletivo, para o realismo é a legitimação da força e força militar, para o liberalismo é o poder compartilhado sob valores e ideais comuns, para o construtivismo é o poder baseado na intersubjetividade das percepções e para o feminismo é a necessidade de feminização do poder.

A conclusão desta síntese das variáveis de cada teoria acerca da segurança nos mostra como cada uma aborda o assunto de uma 
forma particular e a necessidade de um diálogo entre as teorias para que haja a busca por um consenso acerca da segurança a fim de propor benefícios mútuos tanto para os Estados quanto para os indivíduos. 
FIGURA 5: análise das variáveis de segurança

\begin{tabular}{|c|c|c|c|c|c|}
\hline Questions/Focus & Human security & Realist approach & Liberal approach & $\begin{array}{l}\text { Constructivist } \\
\text { approach }\end{array}$ & Feminist approach \\
\hline $\begin{array}{l}\text { State of the } \\
\text { international } \\
\text { system? }\end{array}$ & $\begin{array}{l}\text { Insecurity from } \\
\text { inequity, } \\
\text { injustice, } \\
\text { poverty, health } \\
\text { and environmental } \\
\text { hazards, denial } \\
\text { of human rights } \\
\text { and justice }\end{array}$ & $\begin{array}{l}\text { Anarchy, } \\
\text { competition, and } \\
\text { self-help system } \\
\text { Balance of power }\end{array}$ & $\begin{array}{l}\text { Anarchy, } \\
\text { competition but } \\
\text { some space for } \\
\text { regulation through } \\
\text { multi-lateralism }\end{array}$ & $\begin{array}{l}\text { Anarchy as an } \\
\text { 'inter subjective' } \\
\text { construct that } \\
\text { can be deconstructed } \\
\text { The international } \\
\text { system is based } \\
\text { on communal } \\
\text { interaction }\end{array}$ & $\begin{array}{l}\text { A system based on } \\
\text { the exclusion of } \\
\text { women and } \\
\text { masculinity }\end{array}$ \\
\hline $\begin{array}{l}\text { Central referents } \\
\text { of security? }\end{array}$ & $\begin{array}{l}\text { Individual and } \\
\text { communities }\end{array}$ & $\begin{array}{l}\text { The state and its } \\
\text { expressed } \\
\text { national interest }\end{array}$ & $\begin{array}{l}\text { States and } \\
\text { intermational } \\
\text { institutions, NGOs } \\
\text { and civil society as } \\
\text { well as transnational } \\
\text { groups }\end{array}$ & $\begin{array}{l}\text { Individuals, } \\
\text { groups, NGOs, } \\
\text { the civil } \\
\text { society }\end{array}$ & $\begin{array}{l}\text { Women and } \\
\text { feminist values }\end{array}$ \\
\hline $\begin{array}{l}\text { Determinants of } \\
\text { security? }\end{array}$ & $\begin{array}{l}\text { Economic, } \\
\text { health, and } \\
\text { food security; } \\
\text { environmental, personal, } \\
\text { community and } \\
\text { political } \\
\text { security }\end{array}$ & $\begin{array}{l}\text { State and national } \\
\text { security and } \\
\text { military security }\end{array}$ & $\begin{array}{l}\text { State and market } \\
\text { security; and security } \\
\text { for institutions }\end{array}$ & $\begin{array}{l}\text { Security of } \\
\text { cultural } \\
\text { identities, } \\
\text { ideas and norms }\end{array}$ & $\begin{array}{l}\text { Security and } \\
\text { empowerment of } \\
\text { women and all } \\
\text { subaltern classes }\end{array}$ \\
\hline \multirow[t]{2}{*}{$\begin{array}{l}\text { Aims interests of } \\
\text { the state? }\end{array}$} & $\begin{array}{l}\text { To empower } \\
\text { and protect its } \\
\text { citizens }\end{array}$ & $\begin{array}{l}\text { To ensure } \\
\text { stability and } \\
\text { maximum power } \\
\text { States' interests }\end{array}$ & $\begin{array}{l}\text { To reach military, } \\
\text { economic and } \\
\text { political } \\
\text { interdependence }\end{array}$ & $\begin{array}{l}\text { To change the } \\
\text { aspirations and } \\
\text { perceptions of } \\
\text { the population }\end{array}$ & $\begin{array}{l}\text { To create gender } \\
\text { equity and a } \\
\text { justice based peace } \\
\text { loving state }\end{array}$ \\
\hline & & $\begin{array}{l}\text { determined by } \\
\text { material } \\
\text { conditions }\end{array}$ & $\begin{array}{l}\text { States' interests are } \\
\text { based on values } \\
\text { and institutions }\end{array}$ & $\begin{array}{l}\text { States' } \\
\text { interests } \\
\text { determined by } \\
\text { identity and } \\
\text { culture }\end{array}$ & $\begin{array}{l}\text { Feminist interests } \\
\text { representing civil } \\
\text { society to replace } \\
\text { elitist patriarchal } \\
\text { state interests }\end{array}$ \\
\hline $\begin{array}{l}\text { Security through } \\
\text { which means? }\end{array}$ & $\begin{array}{l}\text { Prevention, } \\
\text { protection, } \\
\text { provision of } \\
\text { human security. } \\
\text { empowerment } \\
\text { of people }\end{array}$ & $\begin{array}{l}\text { Protection of the } \\
\text { state, a zero-sum } \\
\text { game }\end{array}$ & $\begin{array}{l}\text { Cooperation; } \\
\text { institutionalization } \\
\text { and } \\
\text { interdependence }\end{array}$ & $\begin{array}{l}\text { Peaceful } \\
\text { norms and } \\
\text { perceptions, } \\
\text { reconstructed } \\
\text { security } \\
\text { through } \\
\text { international } \\
\text { organizations }\end{array}$ & $\begin{array}{l}\text { Security through } \\
\text { gender rights, } \\
\text { equity, and } \\
\text { empowerment }\end{array}$ \\
\hline $\begin{array}{l}\text { Role of actors in } \\
\text { security? }\end{array}$ & $\begin{array}{l}\text { People and civil } \\
\text { society should } \\
\text { be empowered } \\
\text { and responsible } \\
\text { for human } \\
\text { security }\end{array}$ & $\begin{array}{l}\text { State executives, } \\
\text { military } \\
\text { commanders and } \\
\text { selected experts } \\
\text { oversee national } \\
\text { security }\end{array}$ & $\begin{array}{l}\text { Actors that emerge } \\
\text { from and use } \\
\text { democratic } \\
\text { processes to build } \\
\text { trust }\end{array}$ & $\begin{array}{l}\text { Multiple actors } \\
\text { who work on } \\
\text { the basis of } \\
\text { trust }\end{array}$ & $\begin{array}{l}\text { Women to be } \\
\text { empowered as } \\
\text { equal citizens and } \\
\text { actors. }\end{array}$ \\
\hline $\begin{array}{l}\text { Notion and role } \\
\text { of power? }\end{array}$ & $\begin{array}{l}\text { Power as } \\
\text { collective } \\
\text { principle and } \\
\text { people's power }\end{array}$ & $\begin{array}{l}\text { State has ultimate } \\
\text { power based on } \\
\text { legitimate force } \\
\text { and military } \\
\text { strength } \\
\text { Between states } \\
\text { there is a balance } \\
\text { of power }\end{array}$ & $\begin{array}{l}\text { Power sharing } \\
\text { based on values } \\
\text { and ideals }\end{array}$ & $\begin{array}{l}\text { Power is based } \\
\text { on 'inter- } \\
\text { subjective' } \\
\text { perceptions }\end{array}$ & $\begin{array}{l}\text { Power needs to be } \\
\text { feminized and } \\
\text { negotiated. }\end{array}$ \\
\hline
\end{tabular}

FONTE: Tadjbakhsh (2007) ${ }^{9}$

${ }^{9}$ S/P: Sem Paginação, Livro e-book (Amazon) Download Kindle. 


\section{Considerações finais}

Atualmente a Segurança Humana tem sido definida pelos Direitos Humanos. Sendo a sua essência o respeito aos Direitos e liberdades fundamentais do ser humano. Com a inserção da Segurança Humana em debates internacionais os mantenedores da paz entenderam a sua necessidade e importância no cenário internacional para o desenvolvimento de uma paz sustentável.

A problemática a ser verificada acerca da importância da Segurança Humana no Pós-Guerra Fria é comprovada a partir do apontamento das diversas ameaças ao indivíduo que emergem deste período, tanto diretas, como Guerras Civis, por exemplo, quanto indiretas como a destruição da Amazônia, por exemplo. A importância da Segurança Humana também se verifica pela inserção de novos atores no debate sobre Segurança como no caso do movimento feminista.

A hipótese foi corroborada por meio da análise do feminismo como movimento contribuinte para uma mudança no ponto de vista da Segurança vista pelo prisma tradicional focada nos Estados para uma visão de Segurança mais humanitarista e voltada ao indivíduo. Sendo assim, as duas visões se complementam, ao passo que no século XXI ainda há um grande enfoque dos Estados quanto à soberania, ao mesmo tempo que há uma busca por uma modernização nos mecanismos de Segurança internacionais para que haja o menor dano possível à 
população e respeito aos Direitos Humanos que seria o caso da Segurança Humana.

O objetivo proposto de identificar a transição entre as crises das geopolíticas clássicas para geoeconomia Pós-Guerra Fria foi cumprido. Neste artigo foi utilizado o caso emblemático da África para exemplificar os impactos da geoeconomia na Política Internacional como um fenômeno da desigualdade do Sistema Internacional.

A relação entre conflito e Segurança Humana é que enquanto conflitos forem causados por questões de subdesenvolvimento inerentes a Geoeconomia que dividiu o mundo em centro e periferia, que culminou nas desigualdades hoje existentes no cenário internacional, este fato certamente contribuirá para tornar mais intensa a insegurança humana uma vez que a desintegração acontece. O conflito desumaniza pessoas e tira delas a dignidade, aumenta o sofrimento e traz novos tipos de insegurança e que geralmente continua depois mesmo do conflito ter terminado, embora a promoção da Segurança Humana devesse figurar entre as prioridades do processo de reconstrução pósconflito.

O cenário de Pós-conflito permite oportunidades de mudança e de reforma da sociedade tanto em aspectos políticos, como econômicos, buscando desta forma incluir os excluídos e apagar as inequidades. Os custos dos conflitos para as mulheres em geral é serem refugiadas e encontrarem-se deslocadas, sendo que o estupro e o abuso sexual de 
mulheres ainda tem sido frequentemente usados como instrumentos de poder no conflitos entre comunidades.

Apesar de vermos atualmente o reavivamento das geopolíticas clássicas com a política de Putin na Rússia e a busca pela volta do Império Russo, principalmente com relação a Teoria do Poder Terrestre de Mackinder, o que este artigo se propôs a apresentar e uma nova percepção futura acerca da Segurança. Talvez deixar de investir tanto na segurança militar possa possibilitar que se invista mais na educação, na industrialização, na tecnologia e na pesquisa do país contribuindo para abrir caminhos à Governança Global.

\section{Referências}

ONU. Fim de conflitos na África depende de luta contra pobreza e desigualdade. 2013. Disponível em: http://www.onu.org.br/fim-deconflitos-na-africa-depende-de-luta-contra-pobreza-e-desigualdade-dizonu/. Acesso em: 26 de junho de 2014

SORJ, Bernardo .Segurança, segurança humana e América Latina. Sur. Revista Internacional de Direitos Humanos, São Paulo, v. 3, p. 4159, 2005.

TADJBAKHSH, Shahrbanou. Human security: concepts and implications (Routledge Advances in International Relations and Global Politics). Routledge (January 7, 2007). 272 pages 
VESENTINI, J. W. . Novas Geopolíticas. 1. ed. São Paulo: Contexto, 2000. v. 1. 126p . 